\title{
Is staff consistency important to parents' satisfaction in a longitudinal study of children at risk for type 1 diabetes: the TEDDY study
}

Jessica Melin ${ }^{1 *}$, Kristian F. Lynch², Markus Lundgren ${ }^{1,3}$, Carin Andrén Aronsson ${ }^{1}$, Helena Elding Larsson ${ }^{1,4}$, Suzanne Bennett Johnson ${ }^{5}$ and TEDDY Study Group

\begin{abstract}
Background: Participants' study satisfaction is important for both compliance with study protocols and retention, but research on parent study satisfaction is rare. This study sought to identify factors associated with parent study satisfaction in The Environmental Determinants of Diabetes in the Young (TEDDY) study, a longitudinal, multinational (US, Finland, Germany, Sweden) study of children at risk for type 1 diabetes. The role of staff consistency to parent study satisfaction was a particular focus.

Methods: Parent study satisfaction was measured by questionnaire at child-age 15 months (5579 mothers, 4942 fathers) and child-age four years (4010 mothers, 3411 fathers). Multiple linear regression analyses were used to identify sociodemographic factors, parental characteristics, and study variables associated with parent study satisfaction at both time points.

Results: Parent study satisfaction was highest in Sweden and the US, compared to Finland. Parents who had an accurate perception of their child's type 1 diabetes risk and those who believed they can do something to prevent type 1 diabetes were more satisfied. More educated parents and those with higher depression scores had lower study satisfaction scores. After adjusting for these factors, greater study staff change frequency was associated with lower study satisfaction in European parents (mothers at child-age 15 months: $-0.30,95 \% \mathrm{Cl}-0.36,-0.24, p<$ 0.001 ; mothers at child-age four years: $-0.41,95 \% \mathrm{Cl}-0.53,-0.29, p<0.001$; fathers at child-age 15 months: -0.28 , $95 \% \mathrm{Cl}-0.34,-0.21, p<0.001$; fathers at child-age four years: $-0.35,95 \% \mathrm{Cl}-0.48,-0.21, p<0.001)$. Staff consistency was not associated with parent study satisfaction in the US. However, the number of staff changes was markedly higher in the US compared to Europe.

Conclusions: Sociodemographic factors, parental characteristics, and study-related variables were all related to parent study satisfaction. Those that are potentially modifiable are of particular interest as possible targets of future efforts to improve parent study satisfaction. Three such factors were identified: parent accuracy about the child's type 1 diabetes risk, parent beliefs that something can be done to reduce the child's risk, and study staff consistency. However, staff consistency was important only for European parents.
\end{abstract}

\footnotetext{
* Correspondence: jessica.melin@med.lu.se

'Department of Clinical Sciences, Lund University, Malmö, Sweden

Full list of author information is available at the end of the article
}

(c) The Author(s). 2022 Open Access This article is licensed under a Creative Commons Attribution 4.0 International License, which permits use, sharing, adaptation, distribution and reproduction in any medium or format, as long as you give appropriate credit to the original author(s) and the source, provide a link to the Creative Commons licence, and indicate if changes were made. The images or other third party material in this article are included in the article's Creative Commons licence, unless indicated otherwise in a credit line to the material. If material is not included in the article's Creative Commons licence and your intended use is not permitted by statutory regulation or exceeds the permitted use, you will need to obtain permission directly from the copyright holder. To view a copy of this licence, visit http://creativecommons.org/licenses/by/4.0/ The Creative Commons Public Domain Dedication waiver (http://creativecommons.org/publicdomain/zero/1.0/) applies to the data made available in this article, unless otherwise stated in a credit line to the data. 
Trial registration: NCT00279318.

Keywords: Study satisfaction, Parent satisfaction, Staff consistency, Child, Longitudinal study, Type 1 diabetes, Genetic risk

\section{Background}

Clinical trials are necessary to test various drugs as well as other medical or behavioral interventions. Natural history studies are critical to our understanding of disease etiology and progression. Both place considerable demands on participants who often endure invasive interventions or assessment procedures over long periods of time. Participants' satisfaction with a trial or study experience is likely important to both compliance with the study protocol and study retention. However, few studies have examined study satisfaction and experiences among study participants [1]. This dearth of literature is particularly noteworthy in pediatric populations. Published studies of parent satisfaction focus mostly on the child's care or specific aspects of a study [2-6], but studies of parents' overall satisfaction with a study in which their child is enrolled are limited. The studies that do exist suggest that most participating parents will recommend the study to others and are willing to participate in a new study $[2,5,7]$.

Studies examining factors associated with parent study satisfaction are also limited. Less educated parents and those from racial or ethnic minority groups often report greater satisfaction than higher educated parents or those from the majority culture $[3,8]$. Higher overall satisfaction was also associated with fewer transportation problems and fewer study-related financial difficulties [6]. Most studies examining parent satisfaction do not report differences between mothers' and fathers' satisfaction; studies examining fathers' study satisfaction are rare.

Type 1 diabetes is an autoimmune disease usually diagnosed in childhood; its prevalence is increasing worldwide [9]. Exogenous insulin replacement by injection or insulin pump is necessary for survival and there is no cure for type 1 diabetes. Although children at risk for type 1 diabetes can be identified by genetic and immunologic markers, there currently is no means to prevent the disease in these high-risk children. The Diabetes Prevention Trial (DPT-1) tested both insulin injections and oral insulin as possible prevention strategies in children at risk for type 1 diabetes; neither intervention was effective [10, 11]. Participants' satisfaction was examined in all arms of the study. There was a high level of study satisfaction overall, but some important differences between participants emerged: parents reported greater study satisfaction than children, adult participants reported greater study satisfaction than child participants, and mothers reported greater study satisfaction than fathers $[12,13]$.

The Environmental Determinants of Diabetes in the Young (TEDDY) study was designed to identify environmental triggers of type 1 diabetes in genetically at-risk children from birth to 15 years of age. Using the DPT-1 methodology, TEDDY monitors parent study satisfaction on an ongoing basis and has found it to be associated with both study retention [14] and adherence with OGTT assessments [15], but not food record compliance [16].

The role of study staff as a determinant of participants' study satisfaction seems critical since it is a potentially modifiable component of a study's protocol. Studies suggest that participants were more likely to report greater study satisfaction when they felt the study staff had enough time for them, listened to them, and treated them with respect and friendliness [5, 17-19]. Few studies have examined whether consistency in study staff is important to participants' study satisfaction. In a study examining reasons for retention, $89 \%$ of the parents gave the highest rating "liked a lot" for "seeing the same staff at each visit" [20]. Another study reported frequent staff changes across study visits as one of the top three most negative experiences for participants in a long-term trial [21].

The aim of the current study was to identify factors associated with parent study satisfaction in TEDDY, with a particular focus on the role of staff consistency. The study is unique in that it examines study satisfaction in both mothers and fathers in a multinational study at two points in time: after one year and after 4 years. Furthermore, the availability of psychosocial and sociodemographic variables collected during the TEDDY study permitted an examination of a wide range of factors potentially associated with study satisfaction. Since the different TEDDY countries have different approaches to study staffing, TEDDY data provided an important opportunity to examine the association of staff consistency with parent study satisfaction.

\section{Methods}

\section{The TEDDY study}

The aim of the TEDDY study is to identify environmental triggers of diabetes-related autoimmunity and progression to type 1 diabetes in genetically at-risk children. A total of 8676 children were enrolled in TEDDY before 4.5 months of age. Enrollment occurred during 2004- 
2010 in four different countries: Finland, Germany, Sweden, and the US. Each country's ethical board approved the TEDDY study [22]. Most participants (89\%) have no family members with type 1 diabetes. TEDDY children are followed until type 1 diabetes diagnosis or 15 years of age. The protocol includes four visits per year until four years of age, with visits reduced to two times per year for islet autoantibody-negative children while islet autoantibody-positive children maintain quarterly visits. Study visits include data collection from interviews, questionnaires, blood draws, and nasal swabs.

\section{Study satisfaction}

In TEDDY, overall study satisfaction was measured by questionnaire at a child's 6- and 15-months visits, then annually thereafter. In the present study, we used the data from the 15-month and the four-year questionnaires, since 15 months is one year after enrollment and four years is the end of the quarterly visit schedule for all TEDDY children. Both mothers and fathers were administered the questionnaires. Using the same methodology employed in the DPT-1 [12, 13], study satisfaction was measured by three items: 1) "Overall, how do you feel about having your child participate in the TEDDY study? (scored 2 =like it a lot, 1 =like it a little, $0=$ it is ok or dislike it)," 2) "Do you think your child's participation in TEDDY was a good decision? (scored: 2 = a great decision, 1 = a good decision, $0=$ an ok decision or bad decision)" and 3) "Would you recommend the TEDDY study to a friend? (scored: 2 =yes, 1 =maybe, 0 =no)." Since these items were highly correlated, they were summed to create a total satisfaction score with a range of $0-6$. Reliability estimates for this sample ranged from $\alpha=0.80$ to $\alpha=0.83$.

\section{Study sample/population}

We examined study satisfaction at two different time points: one year (child-age 15 months) and four years after enrollment (child-age 48 months). Out of the 8676 enrolled children, there were 6576 mothers and 5859 fathers at child-age 15 months who had completed the study satisfaction measure. At child-age four years, there were 4744 mothers and 4063 fathers with study satisfaction scores. Parents were excluded if the child was not HLA eligible (child-age 15 months: 56 mothers and 47 fathers; child-age four years: 27 mothers and 22 fathers); the child had maternal autoantibodies at birth (child-age 15 months: 263 mothers and 231 fathers; child-age four years: 176 mothers and 154 fathers; or the child developed islet autoantibodies for type 1 diabetes (child-age 15 months: 678 mothers and 639 fathers; child-age four years: 531 mothers and 476 fathers). The final sample consisted of 5579 mothers and 4942 fathers at child-age
15 months and 4010 mothers and 3411 fathers at childage four years (Fig. 1).

\section{Sociodemographic measures}

Sociodemographic variables collected at study inception included country of residence, child sex, child has a first-degree relative (mother, father, or sibling) with type 1 diabetes (yes/no), parental age at birth of the child, and child ethnic minority status (yes = for USA: the mother was not born in the USA, the mother's first language is not English, or the child is a member of an ethnic minority; for Europe: the country of birth or mother's first language is one other than that of the TEDDY country in which the child is living. Others = no). Additional sociodemographic variables collected at the 9-month visit included parent education (categorized as primary education or some trade school, graduated trade school, graduated college/university or higher), parent's first child (yes/no), and parent's marital status (parents married/living together: yes/no).

\section{Study-related variables Recruitment cohort}

The recruitment cohort was of interest because TEDDY made a protocol change in March 2009 which introduced a study intervention designed to reduce study drop-outs [23]. Consequently, two recruitment cohorts were examined: children enrolled in TEDDY from September 2004-February 2009 and children enrolled from March 2009-February 2010.

\section{Study staff consistency}

Since all personnel working in the TEDDY study have a specific staff code recorded at every study visit, the number of staff changes prior to any given study visit could be examined. For the 15-month analysis, we counted the number of staff changes for that specific family from enrollment to the 15-month visit (from a minimum of 0 to a maximum of 4). For the four-year analysis, we counted the number of staff changes in the year prior to the four-year visit (from a minimum of 0 to a maximum of 3). We also examined the total number of staff changes from study inception to the four-year study visit. However, the number of staff changes in the year prior to the four-year visit proved to be more strongly related to parent study satisfaction and is presented here.

\section{Parent lifestyle behaviors}

At the 9-month study visit, the following parent lifestyle behaviors were collected: smoking (yes/no) and working outside the home (yes/no). 


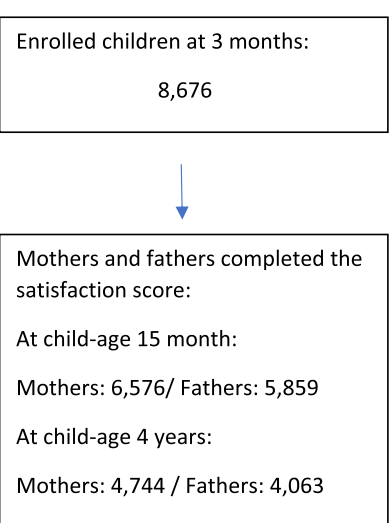

Child had maternal

autoantibodies at birth:

At 15 month:

Mothers: 263/ Fathers: 231

At 4 years:

Mothers: 176 / Fathers: 154

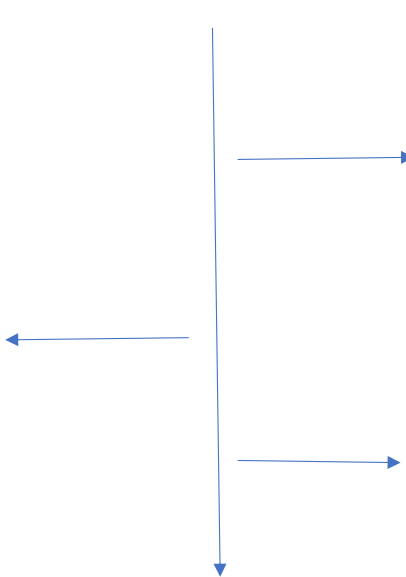

Child HLA not eligible:

At 15 month:

Mothers: 56/ Fathers: 47

At 4 years:

Mothers: 27 /Fathers: 22

Child developed islet autoantibodies

At 15 month:

Mothers: 678/ Fathers: 639

At 4 years:

Mothers: 531/ Fathers: 476

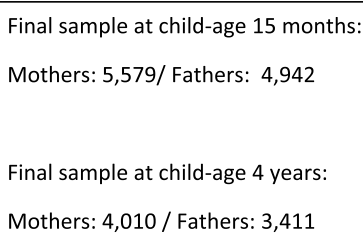

Fig. 1 Flowchart

\section{Parent depression}

The Depression subscale of the Well Being Questionnaire $^{1}$ [24] was collected at the 15 -month visit, than annually thereafter, with higher scores indicating a higher level of depression. The scores obtained at the 15-month and the four-year visit were used in the current analysis. Reliability estimates for this sample ranged from $\alpha=0.62$ to $\alpha=0.69$.

\footnotetext{
${ }^{1}$ The Well Being Questionnaire is licensed by Clare Bradley, HEALTH PSYCHOLOGY RESEARCH LIMITED, (“HPR"), 188 High Street, TW20 9ED, United Kingdom: www.healthpsychologyresearch.com
}

Parent reactions to the TEDDY Child's type 1 diabetes risk Parent reactions to the child's type 1 diabetes risk were assessed at six months, 15 months and annually thereafter. Data collected at the 15-month and four-year visit were used in the current analysis.

\section{Risk perception accuracy}

The accuracy of the parent's perception of the child's risk for type 1 diabetes was assessed by the following item: "Compared to other children, do you think your child's risk for developing diabetes is: much lower, somewhat lower, about the same, somewhat higher, or much higher. Responses of "higher" or "much higher" were 
categorized as accurate, while all other responses were categorized as inaccurate.

\section{Belief that the Child's type 1 diabetes risk can be reduced}

Two questions were used to assess parent beliefs that the child's diabetes risk can be reduced: "I can do something to reduce my child's risk of developing diabetes" and "Medical professionals can do something to reduce my child's risk for developing diabetes." The parent was asked to agree or disagree with each statement on a fivepoint scale, from strongly agree to strongly disagree. The two items were reverse scored and summed to create a total score with a range of $0-8$. A higher score indicated greater belief that the child's risk of type 1 diabetes can be reduced. The coefficient alpha for this sample ranged from $\alpha=0.67$ to $\alpha=0.71$.

\section{Parent anxiety about the Child's risk for type 1 diabetes}

Parent anxiety about the child's risk for type 1 diabetes was measured by a 6-item short form [25] of the State Anxiety component of The State-Trait-Anxiety Inventory for Adults ${ }^{\mathrm{mt}}(\mathrm{STAI})^{2}$ [26]. The measure was designed to specifically assess the parent's anxiety about the child's risk for type 1 diabetes. The 6-item short form score was converted to the 20-item scale score to make it comparable with the larger STAI literature [25]; a higher score indicated higher anxiety. Reliability estimates for this sample ranged from $\alpha=0.90$ to $\alpha=0.91$.

\section{Data analysis}

Comparison of study variables across independent groups were conducted using ANOVA for continuous variables and chi-square for categorical variables. Paired t-tests were used to compare mothers' and fathers' satisfaction scores. Multiple linear regression models were used to identify factors associated with study satisfaction of mothers and fathers separately, when the child was 15 months and four years of age. The analysis was done block by block in the following order: sociodemographic, study-related variables, parent lifestyle behaviors, parent depression, and parent reaction to the child's type 1 diabetes risk. At each step, variables with a $p$ value of $<0.10$ were retained. The final model included all variables with a $p$ value of $<0.05$ in either the mother or father models. Since staff change was markedly higher in the US than Europe, the interaction of staff change by Europe (yes/no) was tested in all final models.

SPSS version 27 (IBM SPSS Statistics for Windows, Armonk, NY: IBM Corp) were used for the statistical analyses.

\footnotetext{
${ }^{2}$ Copyright@ 1968, 1977 by Charles D. Spielberger. State-Trait Anxiety Inventory for Adults ${ }^{\text {Tit }}$ requires license purchase and is a trademark of Mind Garden, Inc.
}

\section{Results}

Descriptive statistics for all study variables at child-age 15 months are provided by country for mothers (Table 1 ) and fathers (Table 2). There were significant country differences for all study variables except child sex and parents living together (fathers only). Noteworthy is the large difference in the number of staff changes in the US compared to Europe. In the first 15 months of the study, there were an average of 2.5 staff changes in the US compared to an average of 1.1 staff changes in Finland and 0.3 staff changes in Sweden (mothers' data), a highly significant difference $(p<0.001$ both for mothers and fathers).

\section{Parent satisfaction score at $\mathbf{1 5}$-months and 4 years}

The parent satisfaction score ranged from 0 to 6 and was skewed in a positive direction. At child-age 15months, $45 \%$ of the mothers and $38 \%$ of the fathers had a score of six, the highest possible satisfaction score. At child-age four years, the results were similar with $48 \%$ of mothers and $40 \%$ of fathers with a score of six. Mothers had higher scores $(\mathrm{M}=4.50,95 \% \mathrm{Cl} 4.46,4.55)$ than fathers $(\mathrm{M}=4.12,95 \% \mathrm{Cl} 4.07,4.17)$ at 15 -months $p<$ 0.001 . The results were similar at four years (mothers: $\mathrm{M}=4.59,95 \% \mathrm{Cl} 4.53,4.64$; fathers: $\mathrm{M}=4.18,95 \% \mathrm{Cl}$ $4.12,4.25, p<0.001)$. A total of 3825 mothers and 3138 fathers completed both the 15-month and four-year satisfaction measure. In this subgroup, parent satisfaction scores remained high over time (mothers: 15-months $\mathrm{M}=4.68,95 \% \mathrm{Cl} 4.62,4.73$ and four-years $\mathrm{M}=4.60,95 \%$ Cl 4.55, 4.66; fathers: 15 -months $\mathrm{M}=4.25,95 \% \mathrm{Cl} 4.19$, 4.31 and four-years $\mathrm{M}=4.20,95 \% \mathrm{Cl} 4.13,4.26$ ).

\section{Variables associated with mothers' study satisfaction}

Table 3 describes the factors associated with mothers' study satisfaction at child-age 15 months and four years. The results were similar at both time-points. Country, mother's education level, parents living together, maternal depression, risk perception accuracy, anxiety about the child's type 1 diabetes risk, and belief that the child's type 1 diabetes risk could be reduced were all associated with mothers' study satisfaction at 15 months and at four years. Swedish and US mothers were more satisfied than Finnish mothers. Mothers with basic primary or trade school education were more satisfied than mothers with a university degree. Mothers living with the child's father were less satisfied than those living apart, and mothers with higher depression subscale scores were less satisfied than those with lower depression scores. Mothers who were accurate about their child's type 1 diabetes risk, those who were less anxious about the risk, and those who believed something could be done to reduce the child's risk were all more satisfied with the TEDDY study. Mothers who were older at the child's birth 
Table 1 Mothers' sample characteristics at child-age 15 months by country

\begin{tabular}{ll}
\hline Variable & US $\boldsymbol{n}=\mathbf{2 2 6 9}$ \\
\hline & $n(\%)$ or mean \\
Demographics: & (SD)
\end{tabular}

Finland $n=1218$ Germany $n=303$ Sweden $n=1794$

$n(\%)$ or mean

(SD)

$n(\%)$ or mean

(SD)

$n(\%)$

(\%) or mean

(SD)

Demographics:

Child sex:

Female

Male

$1112(49.0)$

$1157(51.0)$

$598(49.1)$

$620(50.9)$

$142(46.9)$

$161(53.1)$

First-degree relative with type 1 diabetes:

No

Yes

$2081(91.7)$

$188(8.3)$

$1144(93.9)$

$74(6.1)$

205 (67.7)

$98(32.3)$

Child ethnic minority:

No

Yes

Missing

First child:

No

Yes

Missing

Parents living together:

No

Yes

Missing

Mother's education:

University

Trade School

Basic Primary

Missing

Mother's age at child's birth

\section{Study variables:}

Number of staff member changes:

Recruitment cohort:

Sept 2004-Feb 2009

Mar 2009-Feb 2010

\section{Lifestyle variables:}

Mother smokes:

No

Yes

Missing

Mother works outside home:

No

Yes

Missing

Depression subscale:
$1596(70.3)$

$608(26.8)$

65 (2.9)

1385 (61.0)

$856(37.7)$

$28(1.2)$

$116(5.1)$

2125 (93.7)

$28(1.2)$

1412 (62.2)

$513(22.6)$

$329(14.5)$

$15(0.7)$

2269

$31.0(5.5)$

2141

$2.5(1.3)$

$559(24.6)$

$1139(93.5)$

$33(2.7)$

$46(3.8)$

$662(54.4)$

$536(44.0)$

$20(1.6)$

$34(2.8)$

$1166(95.7)$

$18(1.5)$

723 (59.4)

$371(30.5)$

104 (8.5)

$20(1.6)$

1218

$30.1(4.8)$

1178

$1.1(1.3)$

1005 (82.5)

$213(17.5)$

243 (80.2)

60 (19.8)

252 (83.2)

40 (13.2)

11 (3.6)

156 (51.5)

$136(44.9)$

11 (3.6)

7 (2.3)

285 (94.1)

11 (3.6)

111 (36.6)

145 (47.9)

36 (11.9)

11 (3.6)

303

$32.1(4.8)$

253

$0.8(0.8)$

254 (83.8)

38 (12.5)

11 (3.6)

26 (1.1)

981 (43.2)

1248 (55.0)

40 (1.8)

2266

60 (19.8)
$1710(75.4)$
1068 (87.7)

$133(10.9)$

17 (1.4)

1018 (83.6)

175 (14.4)

25 (2.1)

1218
893 (49.8)

901 (50.2)

1706 (95.1)

88 (4.9)

1648 (91.9)

113 (6.3)

$33(1.8)$

977 (54.5)

804 (44.8)

$13(0.7)$

39 (2.2)

1741 (97.0)

14 (0.8)

$879(49.0)$

310 (17.3)

594 (33.1)

$11(0.6)$

1794

$31.0(4.6)$

1759

$0.3(0.6)$

1446 (80.6)

348 (19.4)

1602 (89.3)

181 (10.1)

$11(0.6)$

1282 (71.5)

497 (27.7)

$15(0.8)$

1793

value

0.817

$<0.001$

$<0.001$

$<0.001$

$<0.001$

$<0.001$

$<0.001$

$<0.001$

$<0.001$

$<0.001$

$<0.001$

$<0.001$ 
Table 1 Mothers' sample characteristics at child-age 15 months by country (Continued)

\begin{tabular}{|c|c|c|c|c|c|}
\hline Variable & US $n=2269$ & Finland $n=1218$ & Germany $n=303$ & Sweden $n=1794$ & $\begin{array}{l}p \\
\text { value }\end{array}$ \\
\hline & $2.8(2.2)$ & $2.8(2.1)$ & $2.7(2.4)$ & $3.8(2.2)$ & \\
\hline \multicolumn{6}{|l|}{ Maternal reaction to child's type 1 diabetes risk: } \\
\hline Risk perception: & & & & & $<0.001$ \\
\hline Underestimate & $934(41.2)$ & $354(29.1)$ & $88(29.0)$ & $831(46.3)$ & \\
\hline Accurate & $1331(58.7)$ & $863(70.9)$ & $213(70.3)$ & $962(53.6)$ & \\
\hline Missing & $4(0.2)$ & $1(0.1)$ & $2(0.7)$ & $1(0.1)$ & \\
\hline Anxiety (STAI): & $225735.5(10.6)$ & $121830.7(7.8)$ & $29936.6(10.5)$ & $178734.0(8.6)$ & $<0.001$ \\
\hline $\begin{array}{l}\text { Belief that child's type } 1 \text { diabetes risk can be } \\
\text { reduced: }\end{array}$ & $22624.4(1.8)$ & $12184.8(1.7)$ & $3034.4(1.9)$ & $17935.2(1.4)$ & $<0.001$ \\
\hline
\end{tabular}

Mothers Excluded: children not HLA eligible, children with positive islet autoantibodies, children with maternal islet autoantibodies at 3 or 6 months and children with no maternal study satisfaction measure at 15 months

reported lower satisfaction scores at 15 months $(p=$ $0.001)$, but not at four years $(p=0.734)$. More frequent staff change was associated with less study satisfaction at 15 months $(-0.04,95 \% \mathrm{Cl}-0.08,0.003, p=0.071)$, but not at four years $(0.01,95 \% \mathrm{Cl}-0.05,0.07, p=0.806)$, although the 15-month study result only approached significance.

\section{Variables associated with fathers' study satisfaction}

The multiple linear regression model results for fathers are provided in Table 4. Similar to the findings for mothers, the variables of country, education level, parental depression, risk perception accuracy, and belief that the child's type 1 diabetes risk could be reduced were all associated with fathers' study satisfaction. At 15 months $(-0.07,95 \% \mathrm{Cl}-0.11,-0.02, p=0.007)$ but not at four years $(-0.02,95 \% \mathrm{Cl}-0.09,0.05, p=0.531)$, fathers were less satisfied if there were greater staff changes since enrollment. There were two additional findings for fathers that did not occur for mothers: fathers with type 1 diabetes in the family were more satisfied $(p=0.006)$ at child-age 15 months, while fathers who smoked were more satisfied with their participation in TEDDY $(p=$ 0.032 ) at child-age 4 years.

\section{Interaction of staff consistency with European versus US sites}

Because of the large differences in staff change frequency between European and US sites, we examined whether staff consistency was differentially important for Europe and the US. The interaction was significant for both mothers and fathers at both 15 months and four years. Consequently, we reran our final models for the US and Europe separately. Staff consistency was important for Europe, but not the US, with greater staff change frequency associated with lower study satisfaction among European mothers (child-age 15 months: - 0.30,95\% Cl $-0.36,-0.24, p<0.001$; child-age four years: $-0.41,95 \%$
$\mathrm{Cl}-0.53,-0.29, p<0.001)$ and fathers (child-age 15 months: $-0.28,95 \% \mathrm{Cl}-0.34,-0.21, p<0.001$; child-age four years: $-0.35,95 \% \mathrm{Cl}-0.48,-0.21, p<0.001$ ). Adjusting for all other variables in the final model, one additional staff change before 15 months of age significantly decreased the mothers' average satisfaction score by -0.30 and fathers' by -0.28 ; at four years the score decreased by -0.41 for mothers and -0.35 for fathers. (Table 5, Fig. 2).

\section{Discussion}

Similar to prior studies of parent study satisfaction [2, 5-7, 21], most TEDDY parents were very satisfied with their study participation; over $45 \%$ of mothers and over $38 \%$ of fathers had the highest possible satisfaction score after 1 year and 4 years in the study. DPT-1 $[12,13]$ used the same questions to measure satisfaction as in this study and their results were similar to ours with high parental satisfaction among both mothers and fathers. In DPT-1, mothers were more satisfied than fathers [13]. Our study showed similar results: mothers' mean satisfaction scores were higher than fathers' at both 15 months and four years. Differences between mothers' and fathers' study satisfaction may be partially explained by mothers' more active role in the study; although many fathers did participate, mothers more often accompanied the child to TEDDY visits.

The TEDDY study is unique in both its monitoring of parental study satisfaction across time and its comprehensive examination of factors potentially related to parent study satisfaction. Factors associated with study satisfaction were similar for mothers and fathers and showed a similar pattern at child-age 15 months and four years.

Like our study, others have reported that lower education level is associated with higher study satisfaction [3, 8]. Being part of a longitudinal study with visits several times per year provides a parent with an opportunity to 
Table 2 Fathers' sample characteristics at child-age 15 months by country

\begin{tabular}{lll}
\hline Variable & US $\boldsymbol{n}=\mathbf{1 8 5 3}$ & Finland $\boldsymbol{n}=\mathbf{1 1 5 2}$ \\
\hline & $\begin{array}{ll}n(\%) \text { or mean } \\
\text { (SD) }\end{array}$ & $\begin{array}{l}n(\%) \text { or mean } \\
\text { (SD) }\end{array}$ \\
Demographics: & &
\end{tabular}

\section{5}

\section{ermany $n=$}

$n$ (\%) or mean

(SD)
Sweden $n=$

1666

$n(\%)$ or mean

(SD)

Demographics:

Child sex:

Female

$902(48.7)$

Male

$951(51.3)$

$565(49.0)$

$587(51.0)$

$135(47.4)$

$150(52.6)$

First-degree relative with type 1 diabetes:

No

Yes

$1686(91.0)$

1079 (93.7)

$167(9.0)$

$73(6.3)$

$194(68.1)$

91 (31.9)

1080 (93.8)

$240(84.2)$

No

$1349(72.8)$

Yes

Missing

$454(24.5)$

$50(2.7)$

First child:

No

Yes

Missing

Parents living together:

No

Yes

Missing

Father's education:

University

Trade School

Basic Primary

Missing

Father's age at child's birth

\section{Study variables:}

Number of staff member changes:

Recruitment cohort:

Sept 2004-Feb 2009

Mar 2009-Feb 2010

\section{Lifestyle variables:}

Father smokes:

No

Yes

Missing

Father works outside home:

No

Yes

Missing

Depression subscale:

$1116(60.2)$

721 (38.9)

$16(0.9)$

25 (1.3)

1810 (97.7)

$18(1.0)$

1116 (60.2)

$378(20.4)$

$326(17.6)$

$33(1.8)$

1820

$33.6(5.9)$

1770

$2.6(1.3)$

1391 (75.1)

$462(24.9)$

952 (82.6)

$200(17.4)$

$590(51.2)$

419 (36.4)

$101(8.8)$

$42(3.6)$

1132

$32.3(5.8)$

1115

$1.1(1.3)$

844 (73.3)

$284(24.7)$

$24(2.1)$

18 (1.0)

$121(6.5)$

1693 (91.4)

39 (2.1)

1849
1653 (89.2)

$82(9.8)$

(1.0)

$(65)$
103 (8.9)

997 (86.5)

$52(4.5)$

1151
35 (12.3)

$10(3.5)$

$143(50.2)$

$132(46.3)$

$10(3.5)$

$1(0.4)$

$274(96.1)$

10 (3.5)

109 (38.2)

131 (46.0)

33 (11.6)

$12(4.2)$

284

$35.3(5.3)$

240

$0.8(0.8)$

227 (79.6)

58 (20.4)

209 (73.3)

66 (23.2)

$10(3.5)$

31 (10.9)

244 (85.6)

$10(3.5)$

284
828 (49.7)

$<0.001$

0.872

$<0.001$

1584 (95.1)

$82(4.9)$

$<0.001$

1536 (92.2)

104 (6.2)

$26(1.6)$

$<0.001$

888 (53.3)

768 (46.1)

$10(0.6)$

0.295

$15(0.9)$

$1640(98.4)$

$11(0.7)$

$<0.001$

647 (38.8)

281 (16.9)

721 (43.3)

$17(1.0)$

1656

$<0.001$

33.5 (5.4)

1640

$<0.001$

$0.3(0.7)$

1337 (80.3)

329 (19.7)

$<0.001$

1481 (88.9)

175 (10.5)

$10(0.6)$

0.006

151 (9.1)

1503 (90.2)

$12(0.7)$

1665 
Table 2 Fathers' sample characteristics at child-age 15 months by country (Continued)

\begin{tabular}{|c|c|c|c|c|c|}
\hline Variable & US $n=1853$ & Finland $n=1152$ & $\begin{array}{l}\text { Germany } n= \\
285\end{array}$ & $\begin{array}{l}\text { Sweden } n= \\
1666\end{array}$ & $\begin{array}{l}p \\
\text { value }\end{array}$ \\
\hline & $2.3(2.0)$ & $2.1(1.8)$ & $2.0(2.1)$ & $3.0(1.9)$ & \\
\hline \multicolumn{6}{|l|}{ Paternal reaction to child's type 1 diabetes risk: } \\
\hline Risk perception: & & & & & $<0.001$ \\
\hline Underestimate & $1025(55.3)$ & $533(46.3)$ & $104(36.5)$ & $895(53.7)$ & \\
\hline Accurate & $825(44.5)$ & $619(53.7)$ & $180(63.2)$ & $770(46.2)$ & \\
\hline Missing & $3(0.2)$ & $0(0.0)$ & $1(0.3)$ & $1(0.1)$ & \\
\hline Anxiety (STAI): & $184133.1(10.9)$ & $114829.3(7.7)$ & $27935.0(10.7)$ & $165431.7(8.2)$ & $<0.001$ \\
\hline $\begin{array}{l}\text { Belief that child's type } 1 \text { diabetes risk can be } \\
\text { reduced: }\end{array}$ & $18504.9(1.8)$ & $11515.2(1.6)$ & $2844.6(1.8)$ & $16615.6(1.4)$ & $<0.001$ \\
\hline
\end{tabular}

Fathers Excluded: children not HLA eligible, children with positive islet autoantibodies, children with maternal islet autoantibodies at 3 or 6 month and children with no father study satisfaction measure at 15 months

Table 3 Final generalized liner models for mothers' satisfaction at child-age 15 months and 4 years

\begin{tabular}{|c|c|c|c|c|c|c|c|c|}
\hline \multirow[t]{2}{*}{ Child-age 15 months: } & \multirow[b]{2}{*}{$n$} & \multirow[b]{2}{*}{$B^{*}$} & \multirow[b]{2}{*}{$95 \% \mathrm{Cl}$} & \multirow[b]{2}{*}{$P$ value } & \multirow{2}{*}{$\begin{array}{l}\text { Child- } \\
\text { age } 4 \\
\text { years: } \\
\frac{n}{n}\end{array}$} & \multirow[b]{2}{*}{$\mathrm{B}^{*}$} & \multirow[b]{2}{*}{$95 \% \mathrm{Cl}$} & \multirow[b]{2}{*}{$P$ value } \\
\hline & & & & & & & & \\
\hline \multicolumn{9}{|l|}{ Country: } \\
\hline Finland & 1156 & & Reference & & 799 & & Reference & \\
\hline US & 2089 & 1.31 & $1.16,1.44$ & $<0.001$ & 1474 & 1.58 & $1.43,1.74$ & $<0.001$ \\
\hline Germany & 245 & 0.26 & $0.03,0.48$ & 0.025 & 155 & 0.46 & $0.18,0.72$ & 0.001 \\
\hline Sweden & 1734 & 1.31 & $1.18,1.44$ & $<0.001$ & 1421 & 1.55 & $1.39,1.67$ & $<0.001$ \\
\hline \multicolumn{9}{|l|}{ First-degree relative with type 1 diabetes: } \\
\hline No & 4819 & & Reference & & 3537 & & Reference & \\
\hline Yes & 405 & 0.14 & $-0.03,0.31$ & 0.103 & 312 & 0.03 & $-0.16,0.22$ & 0.766 \\
\hline \multicolumn{9}{|l|}{ Mother's education: } \\
\hline University & 2977 & & Reference & & 2291 & & Reference & \\
\hline Trade School & 1252 & 0.35 & $0.24,0.46$ & $<0.001$ & 840 & 0.42 & $0.29,0.54$ & $<0.001$ \\
\hline Basic Primary & 995 & 0.42 & $0.29,0.55$ & $<0.001$ & 718 & 0.53 & $0.39,0.68$ & $<0.001$ \\
\hline \multicolumn{9}{|l|}{ Parents living together: } \\
\hline No & 180 & & Reference & & 112 & & Reference & \\
\hline Yes & 5044 & -0.42 & $-0.66,-0.18$ & 0.001 & 3737 & -0.45 & $-0.74,-0.15$ & 0.003 \\
\hline Mother's age at child's birth: & 5224 & -0.02 & $-0.03,-0.01$ & 0.001 & 3849 & -0.002 & $-0.01,0.01$ & 0.734 \\
\hline Number of staff changes in the previous year: & 5224 & -0.04 & $-0.08,0.003$ & 0.071 & 3849 & 0.01 & $-0.05,0.07$ & 0.806 \\
\hline \multicolumn{9}{|l|}{ Mother smokes: } \\
\hline No & 4754 & & Reference & & 3566 & & Reference & \\
\hline Yes & 470 & 0.08 & $-0.07,0.24$ & 0.297 & 283 & 0.17 & $-0.02,0.37$ & 0.080 \\
\hline Maternal depression: & 5224 & -0.05 & $-0.07,-0.03$ & $<0.001$ & 3849 & -0.05 & $-0.08,-0.03$ & $<0.001$ \\
\hline \multicolumn{9}{|l|}{ Mother's perception of child's type 1 diabetes risk: } \\
\hline Underestimate & 2061 & & Reference & & 1460 & & Reference & \\
\hline Accurate & 3163 & 0.18 & $0.09,0.28$ & $<0.001$ & 2389 & 0.27 & $0.16,0.37$ & $<0.001$ \\
\hline Maternal anxiety: & 5224 & -0.01 & $-0.01,-0.002$ & 0.010 & 3849 & -0.01 & $-0.01,-0.001$ & 0.026 \\
\hline Maternal belief that child's type 1 diabetes risk can be reduced: & 5224 & 0.13 & 0.110 .16 & $<0.001$ & 3849 & 0.11 & $0.08,0.14$ & $<0.001$ \\
\hline
\end{tabular}

${ }^{*}=\mathrm{B}$ is the linear model coefficient and is interpreted as difference in mean satisfaction compared to the reference group for categorical variables or difference in mean satisfaction per 1 unit change in parental measure for continuous variables when adjusting for all other variables in model as listed in table 
Table 4 Final generalized liner model for fathers' satisfaction at child-age 15 months and 4 years

\begin{tabular}{|c|c|c|c|c|c|c|c|c|}
\hline Child-age 15 months: & & & & & $\begin{array}{l}\text { Child-age } 4 \\
\text { year: }\end{array}$ & & & \\
\hline & $n$ & $B^{*}$ & $95 \% \mathrm{Cl}$ & $P$ value & $n$ & $B^{*}$ & $95 \% \mathrm{Cl}$ & $P$ value \\
\hline \multicolumn{9}{|l|}{ Country: } \\
\hline Finland & 1057 & & Reference & & 682 & & Reference & \\
\hline US & 1692 & 1.37 & $1.22,1.53$ & $<0.001$ & 1058 & 1.50 & $1.32,1.68$ & $<0.001$ \\
\hline Germany & 226 & 0.92 & $0.66,1.17$ & $<0.001$ & 142 & 0.42 & $0.13,0.72$ & 0.005 \\
\hline Sweden & 1590 & 1.42 & $1.27,1.57$ & $<0.001$ & 1235 & 1.38 & $1.21,1.54$ & $<0.001$ \\
\hline \multicolumn{9}{|l|}{ First-degree relative with type 1 diabetes: } \\
\hline No & 4197 & & Reference & & 2864 & & Reference & \\
\hline Yes & 368 & 0.27 & $0.08,0.46$ & 0.006 & 253 & 0.06 & $-0.15,0.27$ & 0.562 \\
\hline \multicolumn{9}{|l|}{ Father's education: } \\
\hline University & 2325 & & Reference & & 1591 & & Reference & \\
\hline Trade School & 1141 & 0.11 & $-0.02,0.23$ & 0.100 & 746 & 0.33 & $0.19,0.47$ & $<0.001$ \\
\hline Basic Primary & 1099 & 0.19 & $0.05,0.33$ & 0.007 & 780 & 0.52 & $0.37,0.67$ & $<0.001$ \\
\hline \multicolumn{9}{|l|}{ Parents living together: } \\
\hline No & 23 & & Reference & & 9 & & Reference & \\
\hline Yes & 4542 & -0.57 & $-1.28,0.13$ & 0.112 & 3108 & $\overline{-}-79$ & $-1.82,0.24$ & 0.132 \\
\hline Father's age at child's birth: & 4565 & -0.002 & $-0.01,0.01$ & 0.611 & 3117 & 0.003 & $-0.01,0.01$ & 0.586 \\
\hline Number of staff changes in the previous year: & 4565 & -0.07 & $\begin{array}{l}-0.11,- \\
0.02\end{array}$ & 0.007 & 3117 & $\overline{-} 0.02$ & $-0.09,0.05$ & 0.531 \\
\hline \multicolumn{9}{|l|}{ Father smokes: } \\
\hline No & 3920 & & Reference & & 2724 & & Reference & \\
\hline Yes & 645 & 0.05 & $-0.10,0.20$ & 0.534 & 393 & 0.19 & $0.02,0.36$ & 0.032 \\
\hline Paternal depression: & 4565 & -0.05 & $\begin{array}{l}-0.08,- \\
0.02\end{array}$ & $<0.001$ & 3117 & $\overline{-} 0.03$ & $\begin{array}{l}-0.06,- \\
0.01\end{array}$ & 0.019 \\
\hline \multicolumn{9}{|l|}{ Father's perception of child's type 1 diabetes risk: } \\
\hline Underestimate & 2352 & & Reference & & 1570 & & Reference & \\
\hline Accurate & 2213 & 0.48 & $0.34,0.59$ & $<0.001$ & 1547 & 0.19 & $0.08,0.31$ & 0.001 \\
\hline Paternal anxiety: & 4565 & 0.01 & $0.00,0.01$ & 0.071 & 3117 & 0.003 & $-0.003,0.01$ & 0.349 \\
\hline $\begin{array}{l}\text { Paternal belief that child's type } 1 \text { diabetes risk can be } \\
\text { reduced: }\end{array}$ & 4565 & 0.20 & $0.17,0.23$ & $<0.001$ & 3117 & 0.08 & $0.04,0.11$ & $<0.001$ \\
\hline
\end{tabular}

* $=\mathrm{B}$ is the linear model coefficient and is interpreted as difference in mean satisfaction compared to the reference group for categorical variables or difference in mean satisfaction per 1 unit change in parental measure for continuous variables when adjusting for all other variables in model as listed in table

ask questions and talk to professionals about the child's type 1 diabetes risk. Perhaps this is more important to parents with lower education compared to more highly educated parents who may more readily access information elsewhere. The repeated study visits may also provide important support to mothers who are not living with the child's father; these mothers reported greater satisfaction with their study participation.

We found that variables related to parental reactions to their child's type 1 diabetes risk to be associated with study satisfaction. Both parents with accurate risk perception and parents who believed they could do something to prevent their child from developing type 1 diabetes had higher study satisfaction scores. Anxiety about the child's type 1 diabetes risk showed a weaker association. More anxious mothers were less satisfied at both child-age 15 months and 4 years. Father anxiety was weakly associated with study satisfaction at 15 months, but not at 4 years. The accuracy of a parent's perception of their child's diabetes risk is a modifiable variable. Parents participating in the TEDDY study receive information about their child's type 1 diabetes risk at least once a year. Knowing one's child is at risk for a chronic disease may increase a parent's anxiety but also their willingness to continue participating. Knowing that someone is watching for signs and symptom of type 1 diabetes in their child may provide some comfort and a greater sense of satisfaction with study participation. 
Table 5 Association of staff consistency with parent study satisfaction at child-age 15 months and 4 years

\begin{tabular}{|c|c|c|c|c|c|c|c|c|}
\hline & \multicolumn{4}{|l|}{ US: } & Europe: & \multirow[b]{2}{*}{$B^{*}$} & \multirow[b]{2}{*}{$95 \% \mathrm{Cl}$} & \multirow[b]{2}{*}{$p$} \\
\hline & $n$ & $\mathrm{~B}^{*}$ & $95 \% \mathrm{Cl}$ & $p$ & $n$ & & & \\
\hline \multicolumn{9}{|c|}{ Numbers of staff changes at 15 months: } \\
\hline Mothers: & 2089 & 0.01 & $-0,04,0.06$ & 0.591 & 3135 & -0.30 & $-0.36,-0.24$ & $<0.001$ \\
\hline Fathers: & 1692 & -0.04 & $-0.11,0.02$ & 0.195 & 2873 & -0.28 & $-0.34,-0.21$ & $<0.001$ \\
\hline \multicolumn{9}{|c|}{ Number of staff changes at 4 years: } \\
\hline Mothers: & 1474 & 0.06 & $-0.01,0.13$ & 0.085 & 2375 & -0.41 & $-0.53,-0.29$ & $<0.001$ \\
\hline Fathers: & 1058 & 0.02 & $-0.06,0.10$ & 0.626 & 2059 & -0.35 & $-0.48,-0.21$ & $<0.001$ \\
\hline
\end{tabular}

All variables included in Tables 3 and 4 are controlled

* $=\mathrm{B}$ is the linear model coefficient and is interpreted as difference in mean satisfaction compared to the reference group for categorical variables or difference in mean satisfaction per 1 unit change in parental measure for continuous variables when adjusting for all other variables in model as listed in table

The role of study staff in parent study satisfaction is likely influenced by the invasiveness, duration, and frequency of study visits. Previous research has shown that even in studies with a short duration, participants' satisfaction increased when they felt study staff had time for them, listened to them, treated them with respect, and were easy to communicate with $[5,17,19]$. In long-term trials, the consistency of study staff may be particularly important [21]. Prior study participants have expressed feelings of abandonment when their staff were transferred or when the study ended without opportunities for future contact [19]. In our study, we found that staff consistency was associated with European parent study satisfaction at both child-age 15 months and after four years. For these parents, fewer changes in study staff were associated with higher satisfaction scores, although this was not the case among US parents. This result is consistent with a prior report which found that one of the reasons for Swedish families to stay in TEDDY was to be seen by the same staff at all visits [27]. Although the participating countries in TEDDY follow the same study protocol, the operation of study clinics varies markedly. It was more common in European sites for participants to have a dedicated staff person following them though the study. This may be one of the reasons why European parents reported lower study satisfaction when faced with increasing staff changes. In contrast, from study inception, participants in US sites often saw different study staff across visits and were less affected by staff changes. Differences in health care systems may also play a part. European participants were all part of universal health care systems in which most children are followed by the same nurse or pediatrician from birth until they start school. US families have a very different health care experience. Some may see the same pediatrician on a regular basis, but many do not.

The present study had several limitation. We only investigated the importance of staff consistency and did

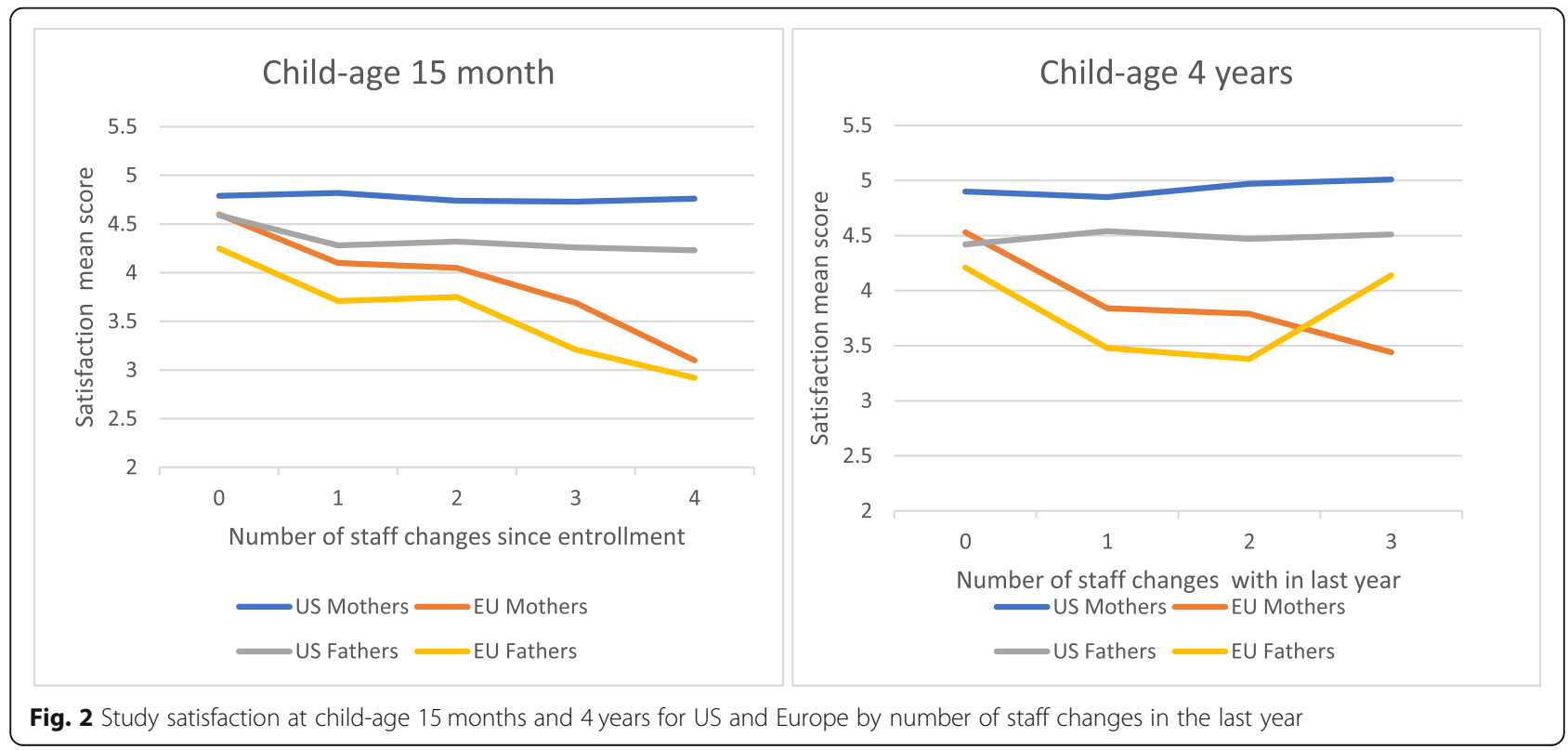


not examine other staff characteristics shown to be important for study satisfaction or study retention, such as staff friendliness or responsiveness to questions [20]. Other studies have suggested that study staff often underestimate the importance of their own role in participant study satisfaction and study retention $[19,20]$. This study is also limited to those who participated in TEDDY for at least one year. Consequently, we do not know if our findings apply to parents who withdrew from TEDDY in the first year. Our study only involved children who were at-risk for type 1 diabetes but did not yet have the disease; whether our findings would be similar for parents of children with diabetes remains to be seen. Similarly, the TEDDY study offers no intervention to prevent the disease. As a consequence, intervention trials may identify different factors associated with parental study satisfaction. However, the association of parent study satisfaction to both study retention and compliance $[14,15,19,20]$, suggests that the identification of factors associated with parent study satisfaction is important to the design of pediatric research studies. This study has numerous strengths in this regard, including a large sample size from four different countries, assessment of both mothers' and fathers' study satisfaction across long periods of time, use of a reliable measure of study satisfaction, and a comprehensive analysis of multiple factors for possible association with parental study satisfaction.

\section{Conclusions}

Sociodemographic factors, parental characteristics, and study-related variables were all related to parent study satisfaction. Those that are potentially modifiable are of particular interest as possible targets of future efforts to improve parent study satisfaction. Three such factors were identified: parent accuracy about the child's type 1 diabetes risk, parent beliefs that something can be done to reduce the child's risk, and study staff consistency. However, staff consistency was important only for European parents.

\section{Abbreviation}

DPT-1: The Diabetes Prevention Trial; TEDDY: The Environmental

Determinants of Diabetes in the Young

\section{Acknowledgments}

The TEDDY Study Group:

Colorado Clinical Center: Marian Rewers, M.D., Ph.D., PI, Aaron Barbour, Kimberly Bautista, Judith Baxter, Daniel Felipe-Morales, Brigitte I. Frohnert, M.D., Marisa Stahl, M.D., Patricia Gesualdo, Rachel Haley, Michelle Hoffman, Rachel Karban, Edwin Liu, M.D., Alondra Munoz, Jill Norris, Ph.D., Stesha Peacock, Hanan Shorrosh, Andrea Steck, M.D., Megan Stern, Kathleen Waugh. University of Colorado, Anschutz Medical Campus, Barbara Davis Center for Childhood Diabetes.

Finland Clinical Center: Jorma Toppari, M.D., Ph.D., Pl, Olli G. Simell, M.D., Ph.D., Annika Adamsson, Ph.D., Sanna-Mari Aaltonen, Suvi Ahonen, Mari Åkerlund, Leena Hakola, Anne Hekkala, M.D., Henna Holappa, Heikki Hyöty, M.D., Ph.D., Anni Ikonen, Jorma Ilonen, M.D., Ph.D., Sanna Jokipuu, Leena Karlsson,
Jukka Kero M.D., Ph.D., Miia Kähönen, Mikael Knip, M.D., Ph.D., Minna-Liisa Koivikko, Katja Kokkonen, Merja Koskinen, Mirva Koreasalo, Kalle Kurppa, M.D., Ph.D., Salla Kuusela, M.D., Jarita Kytölä, Sinikka Lahtinen, Jutta Laiho, Ph.D., Tiina Latva-aho, Laura Leppänen, Katri Lindfors, Ph.D., Maria Lönnrot, M.D., Ph.D., Elina Mäntymäki, Markus Mattila, Maija Miettinen, Katja Multasuo, Teija Mykkänen, Tiina Niininen, Sari Niinistö Mia Nyblom, Sami Oikarinen, Ph.D., Paula Ollikainen, Zhian Othmani, Sirpa Pohjola, Jenna Rautanen, Anne Riikonen, Minna Romo, Satu Simell, M.D., Ph.D., Aino Stenius, Päivi Tossavainen, M.D., Mari Vähä-Mäkilä, Eeva Varjonen, Riitta Veijola, M.D., Ph.D., Irene Viinikangas, Suvi M. Virtanen, M.D., Ph.D.. University of Turku, Tampere University, University of Oulu, Turku University Hospital, Hospital District of Southwest Finland, Tampere University Hospital, Oulu University Hospital, Finnish Institute for Health and Welfare, Finland, University of Kuopio.

Georgia/Florida Clinical Center: Jin-Xiong She, Ph.D., Pl, Desmond Schatz, M.D., Diane Hopkins, Leigh Steed, Jennifer Bryant, Katherine Silvis, Michael Haller, M.D., Melissa Gardiner, Richard McIndoe, Ph.D., Ashok Sharma, Stephen W. Anderson, M.D., Laura Jacobsen, M.D., John Marks, DHSC., P.D. Towe. Center for Biotechnology and Genomic Medicine, Augusta University. University of Florida, Pediatric Endocrinology. Pediatric Endocrine Associates, Atlanta. Germany Clinical Center: Anette G. Ziegler, M.D., PI, Ezio Bonifacio Ph.D., Cigdem Gezginci, Anja Heüblein, Eva Hohoff, Sandra Hummel, Ph.D., Annette Knopff, Charlotte Koch, Sibylle Koletzko, M.D., Claudia Ramminger, Roswith Roth, Ph.D. Jennifer Schmidt, Marlon Scholz, Joanna Stock, Katharina Warncke, M.D., Lorena Wendel, Christiane Winkler, Ph.D. Forschergruppe Diabetes e.V. and Institute of Diabetes Research, Helmholtz Zentrum München, Forschergruppe Diabetes, and Klinikum rechts der Isar, Technische Universität München. Center for Regenerative Therapies, TU Dresden, Dr. von Hauner Children's Hospital, Department of Gastroenterology, Ludwig Maximillians University Munich, University of Bonn, Department of Nutritional Epidemiology. Sweden Clinical Center: Åke Lernmark, Ph.D., Pl, Daniel Agardh, M.D., Ph.D., Carin Andrén Aronsson, Ph.D., Maria Ask, Rasmus Bennet, Corrado Cilio, Ph.D. M.D., Susanne Dahlberg, Malin Goldman Tsubarah, Emelie Ericson-Hallström, Annika Björne Fors, Lina Fransson, Thomas Gard, Monika Hansen, Susanne Hyberg, Berglind Jonsdottir, M.D., Ph.D., Helena Elding Larsson, M.D., Ph.D., Marielle Lindström, Markus Lundgren, M.D., Ph.D., Marlena Maziarz, Ph.D., Maria Månsson Martinez, Jessica Melin, Zeliha Mestan, Caroline Nilsson, Yohanna Nordh, Kobra Rahmati, Anita Ramelius, Falastin Salami, Anette Sjöberg, Carina Törn, Ph.D., Ulrika Ulvenhag, Terese Wiktorsson, Åsa Wimar. Lund University. Washington Clinical Center: William A. Hagopian, M.D., Ph.D., Pl, Michael Killian, Claire Cowen Crouch, Jennifer Skidmore, Christian Chamberlain, Brelon Fairman, Arlene Meyer, Jocelyn Meyer, Denise Mulenga, Nole Powell, Jared Radtke, Shreya Roy, Davey Schmitt, Sarah Zink. Pacific Northwest Research Institute.

Pennsylvania Satellite Center: Dorothy Becker, M.D., Margaret Franciscus, MaryEllen Dalmagro-Elias Smith², Ashi Daftary, M.D., Mary Beth Klein, Chrystal Yates. Children's Hospital of Pittsburgh of UPMC.

Data Coordinating Center: Jeffrey P. Krischer, Ph.D., PI, Rajesh Adusumali, Sarah Austin-Gonzalez, Maryouri Avendano, Sandra Baethke, Brant Burkhardt, Ph.D., Martha Butterworth, Nicholas Cadigan, Joanna Clasen, Kevin Counts, Christopher Eberhard, Steven Fiske, Laura Gandolfo, Jennifer Garmeson, Veena Gowda, Belinda Hsiao, Christina Karges, Qian Li, Ph.D., Shu Liu, Xiang Liu, Ph.D., Kristian Lynch, Ph.D., Jamie Malloy, Cristina McCarthy, Jose Moreno, Hemang M. Parikh, Ph.D., Cassandra Remedios, Chris Shaffer, Susan Smith, Noah Sulman, Ph.D., Roy Tamura, Ph.D., Dena Tewey, Michael Toth, Ulla Uusitalo, Ph.D., Kendra Vehik, Ph.D., Ponni Vijayakandipan, Melissa Wroble, Jimin Yang, Ph.D., R.D., Kenneth Young, Ph.D. Past staff: Michael Abbondondolo, Lori Ballard, Rasheedah Brown, David Cuthbertson, Stephen Dankyi, David Hadley, Ph.D., Kathleen Heyman, Francisco Perez Laras, Hye-Seung Lee, Ph.D., Colleen Maguire, Wendy McLeod, Aubrie Merrell, Steven Meulemans, Ryan Quigley, Laura Smith, Ph.D. University of South Florida.

Project scientist: Beena Akolkar, Ph.D. National Institutes of Diabetes and Digestive and Kidney Diseases.

Other contributors: Thomas Briese, Ph.D., Columbia University. Todd Brusko, Ph.D., University of Florida. Suzanne Bennett Johnson, Ph.D., Florida State University. Eoin McKinney, Ph.D., University of Cambridge. Tomi Pastinen, M.D., Ph.D., The Children's Mercy Hospital. Eric Triplett, Ph.D., University of Florida. Finally, we thank the TEDDY families for their commitment to the study.

\section{Authors' contributions}

JM contributed to the study and analysis design, preformed analysis, conducted the literature search and wrote the manuscript. SBJ contributed 
to the study, analysis design, interpreted data and edited the manuscript. $\mathrm{KL}$ contributed to the study, analysis design, preformed analysis, interpreted data and edited the manuscript. HEL revised the manuscript. ML revised the manuscript. CAA revised the manuscript. All authors read and approved the final manuscript.

\section{Funding}

The TEDDY Study is funded by U01 DK63829, U01 DK63861, U01 DK63821, U01 DK63865, U01 DK63863, U01 DK63836, U01 DK63790, UC4 DK63829, UC4 DK63861, UC4 DK63821, UC4 DK63865, UC4 DK63863, UC4 DK63836, UC4 DK95300, UC4 DK100238, UC4 DK106955, UC4 DK112243, UC4 DK117483, U01 DK124166, U01 DK128847, and Contract No. HHSN267200700014C from the National Institute of Diabetes and Digestive and Kidney Diseases (NIDDK), National Institute of Allergy and Infectious Diseases (NIAID), Eunice Kennedy Shriver National Institute of Child Health and Human Development (NICHD), National Institute of Environmental Health Sciences (NIEHS), Centers for Disease Control and Prevention (CDC), and JDRF. This work is supported in part by the NIH/NCATS Clinical and Translational Science Awards to the University of Florida (UL1 TR000064) and the University of Colorado (UL1 TR002535). The content is solely the responsibility of the authors and does not necessarily represent the official views of the National Institutes of Health. Open Access funding provided by Lund University.

\section{Availability of data and materials}

The datasets generated and analyzed during the current study will be made available in the NIDDK Central Repository at https://repository.niddk.nih.gov/ studies/teddy.

\section{Declarations}

\section{Ethics approval and consent to participate}

Each country's Ethics Committee or Institutional Review Board approved the TEDDY study.

\section{Consent for publication}

Not applicable.

\section{Competing interests}

The authors declare that they have no competing interests.

\section{Author details}

${ }^{1}$ Department of Clinical Sciences, Lund University, Malmö, Sweden. ${ }^{2}$ Health Informatics Institute, Morsani College of Medicine, University of South Florida, Tampa, FL, USA. ${ }^{3}$ Department of Pediatrics, Kristianstad hospital, Kristianstad, Sweden. ${ }^{4}$ Department of Pediatrics, Skåne University Hospital, Malmö, Sweden. ${ }^{5}$ Department of Behavioral Sciences and Social Medicine, Florida State University College of Medicine, Tallahassee, FL, USA.

\section{Received: 26 October 2021 Accepted: 28 December 2021}

\section{Published online: 10 January 2022}

\section{References}

1. Planner C, Bower P, Donnelly A, Gillies K, Turner K, Young B. Trials need participants but not their feedback? A scoping review of published papers on the measurement of participant experience of taking part in clinical trials. Trials. 2019;20(1):381. https://doi.org/10.1186/s13063-019-3444-y.

2. Rundberg-Rivera EV, Townsend LD, Schneider J, Farmer CA, Molina BB, Findling RL, et al. Participant satisfaction in a study of stimulant, parent training, and risperidone in children with severe physical aggression. J Child Adolesc Psychopharmacol. 2015;25(3):225-33. https://doi.org/10.1089/cap.2 014.0097.

3. Tierney E, Aman M, Stout D, Pappas K, Arnold LE, Vitiello B, et al. Parent satisfaction in a multi-site acute trial of risperidone in children with autism: a social validity study. Psychopharmacology. 2007;191(1):149-57. https://doi. org/10.1007/s00213-006-0604-z.

4. Grey I, Coughlan B, Lydon H, Healy O, Thomas J. Parental satisfaction with early intensive behavioral intervention. J Intellect Disabil. 2017; 1744629517742813(3):373-84. https://doi.org/10.1177/1744629517742813.
5. Mazlan R, Hickson L, Driscoll C. Measuring parent satisfaction with a neonatal hearing screening program. J Am Acad Audiol. 2006;17(4):253-64. https://doi.org/10.3766/jaaa.17.4.4.

6. Martin S, Gillespie A, Wolters PL, Widemann BC. Experiences of families with a child, adolescent, or young adult with neurofibromatosis type 1 and plexiform neurofibroma evaluated for clinical trials participation at the National Cancer Institute. Contemp Clin Trials. 2011;32(1):10-5. https://doi. org/10.1016/j.cct.2010.10.004.

7. Zaitoun M, Nuseir A. Parents' satisfaction with a trial of a newborn hearing screening programme in Jordan. Int J Pediatr Otorhinolaryngol. 2020;130: 109845. https://doi.org/10.1016/j.ijporl.2019.109845.

8. Salaets T, Lavrysen E, Smits A, Vanhaesebrouck S, Rayyan M, Ortibus E, et al. Parental perspectives long term after neonatal clinical trial participation: a survey. Trials. 2020;21(1):907. https://doi.org/10.1186/s13 063-020-04787-0.

9. Patterson CC, Karuranga S, Salpea P, Saeedi P, Dahlquist G, Soltesz G, et al. Worldwide estimates of incidence, prevalence and mortality of type 1 diabetes in children and adolescents: Results from the International Diabetes Federation Diabetes Atlas, 9th edition. Diabetes Res Clin Pract. 2019;157:107842.

10. Diabetes Prevention Trial--Type 1 Diabetes Study G. Effects of insulin in relatives of patients with type 1 diabetes mellitus. N Engl J Med. 2002; 346(22):1685-91.

11. Skyler JS, Krischer JP, Wolfsdorf J, Cowie C, Palmer JP, Greenbaum C, et al. Effects of oral insulin in relatives of patients with type 1 diabetes: the diabetes prevention trial--type 1. Diabetes Care. 2005;28(5):1068-76. https:// doi.org/10.2337/diacare.28.5.1068.

12. Johnson SB, Baughcum AE, Hood K, Rafkin-Mervis LE, Schatz DA, Group DPTS. Participant and parent experiences in the parenteral insulin arm of the diabetes prevention trial for type 1 diabetes. Diabetes Care. 2007;30(9): 2193-8. https://doi.org/10.2337/dc06-2422.

13. Johnson SB, Baughcum AE, Rafkin-Mervis LE, Schatz DA, Group DPTS. Participant and parent experiences in the oral insulin study of the diabetes prevention trial for type 1 diabetes. Pediatr Diabetes. 2009;10(3):177-83. https://doi.org/10.1111/j.1399-5448.2008.00463.x.

14. Johnson SB, Lynch KF, Baxter J, Lernmark B, Roth R, Simell T, et al. Predicting later study withdrawal in participants active in a longitudinal birth cohort study for 1 year: the TEDDY study. J Pediatr Psychol. 2016;41(3):373-83. https://doi.org/10.1093/jpepsy/jsv092.

15. Driscoll KA, Tamura R, Johnson SB, Gesualdo P, Clasen J, Smith L, et al. Adherence to oral glucose tolerance testing in children in stage 1 of type 1 diabetes: the TEDDY study. Pediatr Diabetes. 2021;22(2):360-8. https://doi. org/10.1111/pedi.13149.

16. Yang J, Lynch KF, Uusitalo UM, Foterek K, Hummel S, Silvis K, et al. Factors associated with longitudinal food record compliance in a paediatric cohort study. Public Health Nutr. 2016;19(5):804-13. https://doi.org/10.1017/S13 68980015001883.

17. Pflugeisen BM, Rebar S, Reedy A, Pierce R, Amoroso PJ. Assessment of clinical trial participant patient satisfaction: a call to action. Trials. 2016;17(1): 483. https://doi.org/10.1186/s13063-016-1616-6.

18. Verheggen FW, Nieman FH, Reerink E, Kok GJ. Patient satisfaction with clinical trial participation. Int J Qual Health Care. 1998;10(4):319-30. https:// doi.org/10.1093/intahc/10.4.319.

19. Kost RG, Lee LM, Yessis J, Coller BS, Henderson DK. Research participant perception survey focus group S. assessing research participants' perceptions of their clinical research experiences. Clin Transl Sci. 2011;4(6): 403-13. https://doi.org/10.1111/j.1752-8062.2011.00349.x.

20. Dias L, Schoenfeld E, Thomas J, Baldwin C, McLeod J, Smith J, et al. Reasons for high retention in pediatric clinical trials: comparison of participant and staff responses in the correction of myopia evaluation trial. Clin Trials. 2005; 2(5):443-52. https://doi.org/10.1191/1740774505cn113oa.

21. Henzlova MJ, Blackburn GH, Bradley EJ, Rogers WJ. Patient perception of a long-term clinical trial: experience using a close-out questionnaire in the studies of left ventricular dysfunction (SOLVD) trial. SOLVD close-out working group. Control Clin Trials. 1994;15(4):284-93. https://doi.org/10.101 6/0197-2456(94)90044-2.

22. Teddy Study $\mathrm{G}$. The environmental determinants of diabetes in the Young (TEDDY) study: study design. Pediatr Diabetes. 2007;8(5):286-98. https://doi. org/10.1111/j.1399-5448.2007.00269.x.

23. Johnson SB, Lynch KF, Lee HS, Smith L, Baxter J, Lernmark B, et al. At high risk for early withdrawal: using a cumulative risk model to increase retention 
in the first year of the TEDDY study. J Clin Epidemiol. 2014;67(6):609-11. https://doi.org/10.1016/j.jclinepi.2014.01.004.

24. Bradley C, Lewis KS. Measures of psychological well-being and treatment satisfaction developed from the responses of people with tablet-treated diabetes. Diabet Med. 1990;7(5):445-51. https://doi.org/10.1111/j.1464-5491.1 990.tb01421.x.

25. Hood KK, Johnson SB, Baughcum AE, She JX, Schatz DA. Maternal understanding of infant diabetes risk: differential effects of maternal anxiety and depression. Genet Med. 2006;8(10):665-70. https://doi.org/10.1097/01. gim.0000237794.24543.4d.

26. Spielberger CD, Gorsuch RL, Lushene R. Test manual for the form X statetrait anxiety inventory. Palo Alto: Consulting Psychologists Press; 1970.

27. Lernmark B, Lynch K, Ballard L, Baxter J, Roth R, Simell T, Johnson SB.

Reasons for Staying as a Participant in the Environmental Determinants of Diabetes in the Young (TEDDY) Longitudinal Study. J Clin. 2012;2(2): 1000114. https://doi.org/10.4172/2167-0870.1000114.

\section{Publisher's Note}

Springer Nature remains neutral with regard to jurisdictional claims in published maps and institutional affiliations.

Ready to submit your research? Choose BMC and benefit from:

- fast, convenient online submission

- thorough peer review by experienced researchers in your field

- rapid publication on acceptance

- support for research data, including large and complex data types

- gold Open Access which fosters wider collaboration and increased citations

- maximum visibility for your research: over $100 \mathrm{M}$ website views per year

At BMC, research is always in progress.

Learn more biomedcentral.com/submissions 